\title{
High-Power Millimeter-Wave Transmitter for the NRL WARLOC Radar
}

M. T. Ngo*, B.G. Danly*, R. Myers ${ }^{+}$, D.E. Pershing", V. Gregers-Hansen, and G. Linde

\author{
US Naval Research Laboratory \\ 4555 Overlook Ave., SW \\ Washington, DC 20375
}

\section{A. Introduction}

High power millimeter wave instrumentation radars have a number of important applications ranging from defense missions to basic scientific studies [1,2]. At the Naval Research Laboratory, a new high power $94 \mathrm{GHz}$ radar named WARLOC has been developed. This radar employs a high power gyro-klystron as the final power amplifier and was developed during 1996-2001. The WARLOC radar has been integrated as a transportable system, using the 100 $\mathrm{kW}$ peak, $10 \mathrm{~kW}$ average power gyro-klystron amplifier, a low-loss transmission line, a quasioptical duplexer, and a Cassegrain antenna. The transmitter operation and waveguide system is the subject of this paper. The system is housed in two trailers as shown in Figure 1. The larger trailer, with the antenna pedestal mounted at one end, houses the full transmitter and the auxiliary cooling systems for the radar. The smaller van contains operator controls and the signal processing and computer systems.

\section{B. WARLOC Transmitter Components}

\section{Gyro-Klystron based Transmitter}

The W-band ( $94 \mathrm{GHz}$ ) gyro-klystron amplifier was developed over a number of years in two stages, as a joint effort between NRL, Communications and Power Industries (CPI), Litton EDD, and the University of Maryland for the first prototype development $[3,4]$, and by NRL and CPI for the more recent improvements to the gyro-klystron technology [5]. The second gyro-klystron, VGB$8194 \mathrm{SN} 2$, is a five-cavity amplifier, producing 100 $\mathrm{kW}$ peak output power in the $\mathrm{TE}_{01}$ output mode at $10 \%$ duty factor with a $3-\mathrm{db}$ bandwidth of $700 \mathrm{MHz}$ and a saturated gain of $33 \mathrm{~dB}$. The gyro-klystron is

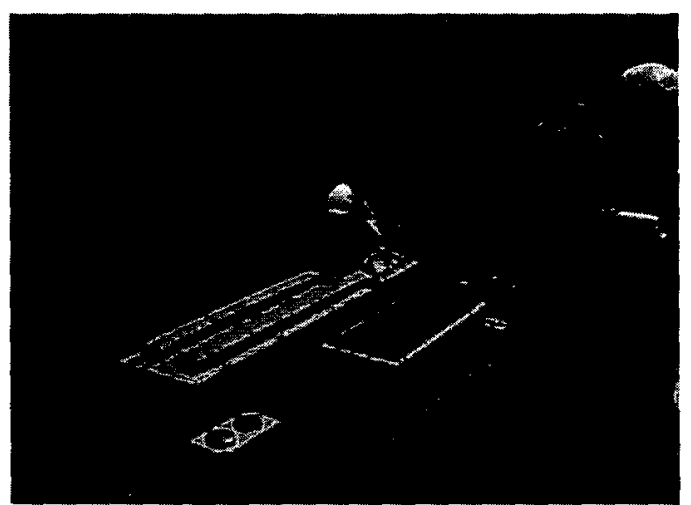

Figure 1. WARLOC radar system at the NRL Chesapeake Beach Detachment site. driven by a intermediate power amplifier consisting of a coupled-cavity TWT (CPI VTW6495B2) and a power supply/modulator (Pulse Technology, Inc). The 65-kV pulse modulator system for the gyro-klystron was built by ETM Electromatics. The gyroklystron transmitter is now operational in the WARLOC radar, having been run at up to $3.3 \mathrm{~kW}$ average power in initial testing. This average power limitation was self-imposed and not a result of limitations to the gyroklystron performance. Radar testing is proceeding. Additional test results will be presented at the conference.

\footnotetext{
*Also with Mission Research Corp, Newington, VA, ngo@mmace.nrl.navy.mil, pershing@mmace.nrl.navy.mil

• danly@nrl.navy.mil FAX:202-767-1280, Phone 202-767-0032 (corresponding author)

${ }^{+}$Also with Dyncorp, EENSP, Alexandria, VA, myers@mmace.nrl.navy.mil

vgh@radar.nrl.navy.mil

•linde@radar.nrl.navy.mil
} 


\section{Over-Moded Transmission Line and Quasi-Optical Duplexer}

The transmission line, which delivers the high average power from the gyro-klystron to the duplexer and antenna, was developed by General Atomics, San Diego. The transmission line components include a mode transformer from $\mathrm{TE}_{01}$ to $\mathrm{HE}_{11}$ mode, circularly-polarizing and nonpolarizing $\mathrm{HE}_{11}$-mode miter bends in $3.175 \mathrm{~cm}$ ID corrugated waveguide[6,7], and rotary joints for azimuth and elevation rotations. The total transmission line length is approximately $11 \mathrm{~m}$. The transmission line insertion loss of about $0.8 \mathrm{~dB}$ was measured. The duplexer, which separates the transmitted power from the received power by means of different polarizations and a nonreciprocal faraday rotator, was developed by MIT Lincoln Laboratory, with assistance from NRL. The duplexer takes the $\mathrm{HE}_{11}$ mode output of the transmission line and delivers it to the sub-reflector of the antenna, while providing for separate transmit and receive paths. The duplexer has a transmit path loss of $0.6 \mathrm{~dB}$ as measured at MIT Lincoln Laboratory.

\section{Summary}

The W-band gyro-klystron based transmitter has been successfully integrated into the NRL WARLOC radar at the NRL Chesapeake Beach Detachment facility. Preliminary operation of the WARLOC radar system was begun in November 2001.

\section{Acknowledgements}

This work is supported by the Office of Naval Research. Mission Research Corp. work is carried out under NRL contract N00014-97-C-2003, and Dyncorp EENSP work is carried out under NRL contract N00173-98-C-2028. The authors would like to acknowledge the expert technical assistance of J. Cameron, G. Longrie, F. Robertson, B. Sobocinski, and F. Wood. The encouragement and support of the NRL Radar Division is also acknowledged.

\section{References}

[1] Abouzahra, M. D. and Avent, R. K., "The 100 kW Millimeter-Wave Radar at the Kwajalein Atoll," IEEE Antennas and Propagation Magazine, vol. 36, no. 2, pp. 7-19, 1994.

[2] Tolkachev, A. A., Levitan, B. A., Solovjev, G. K., Veytsel, V. V., and Farber, V. E., "A Megawatt Power Millimeter-Wave Phased-Array Radar," IEEE AES Systems Magazine, vol. July pp. 25-31, 2000.

[3] Blank, M., Danly, B. G., Levush, B., Calame, J. P., Nguyen, K. T., Pershing, D. E., Petillo, J., Hargreaves, T. A., True, R. B., Theiss, A. J., Good, G. R., Felch, K. L., James, B. G., Borchard, P., Cahalan, P., Chu, T. S., Jory, H. R., Lawson, W. G., and Antonsen, T. M., Jr., "Demonstration of a 10 kW Average Power 94 GHz Gyroklystron Amplifier," Phys.Plasmas, vol. 6, no. 12, pp. 4405-4409, 1999.

[4] Danly, B. G., Blank, M., Calame, J. P., Levush, B., Nguyen, K. T., Pershing, D. E., Parker, R. K., Felch, K. L., James, B. G., Borchard, P., Chu, T. S., Jory, H. R., Hargreaves, T. A., True, R. B., Lawson, W. G., and Antonsen, T. M., Jr., "Development and Testing of a High-Average Power, 94 GHz Gyroklystron," IEEE Transactions on Plasma Science, vol. 28, no. 3, pp. 713-726, 2000.

[5] Blank, M., Felch, K. L., James, B. G., Borchard, P., Cahalan, P., Chu, T. S., Jory, H. R., Danly, B. G., Levush, B., Calame, J. P., Nguyen, K. T., and Pershing, D. E., "Development and demonstration of high average power W-band gyro-amplifiers for radar applications," IEEE Transactions on Plasma Science, Submitted for Publication, 2002.

[6] Doane, J. L., "Propagation and Mode Coupling in Corrugated and Smooth-Wall Circular Waveguides," Millimeter Components and Techniques, Part IV Academic Press, 1985, pp. 123-170. [7] Doane, J. L., "Grating Polarizers in Waveguide Miter Bends," Int.J.Infrared Millimeter Waves, vol. 13 , no. 11, pp. 1727-1743, 1992. 